\title{
Comparison of the prognostic value of SYNTAX score and clinical SYNTAX score on outcomes of Chinese patients underwent percutaneous coronary intervention
}

\author{
Xiao-Qin Li ${ }^{\dagger}$, Chun Yin ${ }^{\dagger}$, Xiao-Li Li, Wen-Li Wu and Kun Cui
}

\begin{abstract}
Background: Previous studies have validated the capability of SYNTAX score (SS) and clinical SYNTAX score (CSS) in the prediction of clinical outcomes in patients who have undergone PCl; however, studies on comparison of these two scoring systems in Chinese population have been sparse.

Methods: To study the ability of SS and CSS in prediction of clinical outcomes of Chinese patients underwent percutaneous coronary intervention (PCI). We retrospectively calculated SS and CSS for 547 Chinese patients from a single center who underwent PCI. Patients were stratified into tertiles according to their SS and CSS. We compared the 2-year clinical outcomes in these patients stratified separately by SS and CSS tertiles.

Results: The incidence of major adverse cardiac and cerebro-vascular events (MACCE) was the highest in patients with $\mathrm{SS}_{\mathrm{HIGH}}(13.5 \%)$, comparing to $6.8 \%$ in $\mathrm{SS}_{\text {MED }}$ and $0 \%$ in SS $\mathrm{SS}_{\text {LOW }}(p<0.0001)$. The Cox multivariable analysis showed that the SS and CSS were both strong independent predictors for MACCE [1.100 (1.069-1.133), 1.017 (1.010-1.025), both $p<0.0001]$. The receiver operating characteristic (ROC) curves showed the areas-under-the-curves for all-cause death by CSS was slightly larger comparing to SS but not significantly (AUC SS, 0.64; AUC CSS, 0.71; $p=0.23$ ).

Conclusion: We concluded that both the SS and CSS were capable of risk stratification of clinical outcomes in allcomers population as well as in low and moderate risk Chinese patients undergoing PCI with CSS showing slightly better advantage.
\end{abstract}

Keywords: SYNTAX score, Clinical SYNTAX score, Percutaneous coronary intervention, Clinical outcomes

\section{Background}

Percutaneous coronary intervention (PCI) is the major strategy in treating coronary artery disease $(C A D)$ which is a leading cause of human death. The Synergy between PCI with Taxus and Cardiac Surgery score (SYNTAX

\footnotetext{
*Correspondence: cuikun@ucas.edu.cn

${ }^{\dagger}$ Xiao-Qin Li and Chun Yin have contributed equally to this work and should be considered co-first authors

Department of Cardiology, Chongqing General Hospital, University of Chinese Academy of Sciences, No. 108, Xingguang Road, Liangjiang New District, Chongqing, China
}

score, or SS) is an angiographic scoring system which is based on the complexity of coronary lesions $[1,2]$. In clinical practice, SS is being used to help with the decision-making between PCI and coronary artery bypass graft (CABG) surgery and to predict the prognostic outcomes. In the SYNTAX trial [3], SS has been proven to be effective in predicting the clinical outcomes in patients with three-vessel and/or left main coronary artery disease after PCI $[4,5]$. The ability of SS to risk stratify patients has been evaluated in numerous studies, including those with an all-comers design, as well as those only 
enrolling patients with 3-vessel and/or left main disease [6-8].

However, SS does not take into account of other clinical factors, such as those included in the ACEF (age [9], creatinine [10], and ejection fraction [11]) score, which could significantly impact the prediction of prognostic outcomes [12-14]. To overcome this limitation, clinical SYNTAX score (CSS) was proposed, which incorporates clinical variables in addition to angiographic variables. CSS had been shown to improve the predictive ability for adverse clinical outcomes in patient underwent PCI [15, 16]. However, these risk scoring models were more frequently used in high risk (3-vessel and/or left main coronary artery disease) patients treated by PCI, few studies included a study population composed of a majority of low and moderate risk patients. Moreover, CSS is sparsely tested on Chinese population. China has a population of 1.4 billion. This is almost one fifth of the world's total population. Importantly, among 1.4 billion Chinese people, the vast majority (1.3 billion) belong to the Han people, which is the world's largest ethnicity. This situation is very different from other countries, like the US, where multiple ethnicities make up considerable percentages of the total population. Due to this huge population base and the domination of Han people, most populationbased studies need to be tested in Chinese-dominated population to prove their applicability to Chinese people.

Thus, the current study was designed to address the following aims: (1) to validate and compare the performance of the SS with the CSS in all comer Chinese patients who have successfully undergone PCI; (2) to evaluate whether the CSS risk model has improved performance in prediction of adverse outcomes in patients after incorporating clinical information, especially in low and moderate risk patients after PCI.

\section{Methods}

\section{Study design and patient population}

In the current study, a total of 547 patients with chronic stable CAD or acute coronary syndromes who successfully received PCI procedure from June 2014 to November 2017 in the Second Affiliated Hospital of Chongqing Medical University (Chongqing, China) was enrolled. All patients had at least one lesion with diameter stenosis (DS) greater than $50 \%$ in a blood vessel suitable for stent implantation (reference diameter between 2.25 and $4.00 \mathrm{~mm}$ ). No restrictions for the number of lesions, number of treated vessels or stents implanted was set in current study. The primary criteria for exclusion were: pregnancy; allergy to contrast media, previous history of coronary artery bypass grafting (CABG), any planned surgery within 6 months of PCI (unless the patients will maintain dual antiplatelet therapy throughout the peri-operative period); or the participation in another trial before reaching the primary endpoint.

\section{Procedures}

All patients received anticoagulation treatment as follows: clopidogrel $75 \mathrm{mg} /$ day together with aspirin $100 \mathrm{mg} /$ day, more than $24 \mathrm{~h}$ in advance before PCI procedure. During the primary PCI, unfractionated heparin (70-100 U/kg) was used for all patients. For patients with acute coronary syndromes requiring emergency PCI, Clopidogrel $600 \mathrm{mg}$ loading dose and glycoprotein IIb/ IIIa inhibitors were used. The selection of drug-eluting stents and adjunctive devices was at the operators' own discretion. To deploy stents, high pressure balloon dilatation method was used to achieve optimal stent apposition. PCI was deemed angiographically successful if residual stenosis was less than $30 \%$ and the restoration of coronary TIMI (thrombolysis in myocardial infarction) 3 flow at the end stage of the procedure. Five out of 547 patients had coronary dissection, 28 out of 547 patients had side-branch occlusion, coronary perforation cases were rare and considered unsuccessful PCI, thus were not included in the study. All discharged patients were prescribed with clopidogrel $75 \mathrm{mg} /$ day for at least 12 months together with lifelong aspirin at a dose of $100 \mathrm{mg} /$ day. Patients were requested to return for a routine in-hospital follow-up at 1 month, 6 months and 12 months after discharge and additional telephonic follow-ups were performed for up to 2 years. Medical records were reviewed in addition to telephone follow-up of patients to confirm the occurrence of endpoints.

\section{Calculation of SS and CSS}

Two cardiologists adjudicated the angiographic features of each patient with very good agreement (kappa index $=0.81$ ). In case discrepancies occur, a third cardiologist was invited to reach consensus. The SS for each patient was calculated by scoring all coronary lesions with a DS $\geq 50 \%$ in vessels $\geq 2.25 \mathrm{~mm}$ as has been instructed on the SYNTAX score website (www.synta xscore.com). The demographic characteristics of each participating patient, together with their history of heart diseases, and related risk factors were collected and archived upon admission. The Age, Creatinine, and Ejection Fraction (ACEF) score was calculated by patients' left ventricular ejection fraction, age, and creatinine clearance [16]. The CSS was calculated by multiplying the modified ACEF score with SS (CSS $=[S S] \times[$ modified ACEF score]) according to previous publications [16].

\section{Endpoint and definitions}

The primary endpoint of this study included cardiac death, stroke, Myocardial infarction (MI) and any repeat 
Table 1 Baseline clinical characteristics and risk factors

\begin{tabular}{|c|c|c|c|c|c|}
\hline Variable & $\mathrm{SS}_{\text {low }} \leq 8(177)$ & $8<\mathrm{SS}_{\text {mid }}<18(177)$ & $18 \leq \mathrm{SS}_{\text {high }}(193)$ & Total & $p$ value \\
\hline \multicolumn{6}{|l|}{ Baseline characteristics } \\
\hline Male sex & $108(61.0 \%)$ & $123(69.5 \%)$ & $142(73.6 \%)$ & $373(68.2 \%)$ & 0.031 \\
\hline Age (years) & $65.11 \pm 4.00$ & $68.20 \pm 8.19$ & $66.92 \pm 3.00$ & $66.82 \pm 3.50$ & 0.045 \\
\hline Body mass index $\left(\mathrm{kg} / \mathrm{m}^{2}\right)$ & $24.26 \pm 3.07$ & $23.52 \pm 2.98$ & $23.97 \pm 3.12$ & $23.67 \pm 2.12$ & 0.211 \\
\hline \multicolumn{6}{|l|}{ Risk factors } \\
\hline Left ventricular ejection fraction & $67.17 \pm 10.38$ & $69.74 \pm 8.66$ & $65.71 \pm 9.68$ & $67.71 \pm 7.63$ & $<0.001$ \\
\hline Creatinine clearance, $\mathrm{ml} / 1.73 \mathrm{~m}^{2}$ & $64.41 \pm 37.32$ & $57.41 \pm 25.14$ & $56.53 \pm 26.87$ & $58.53 \pm 16.65$ & 0.06 \\
\hline Creatinine $>100 \mu \mathrm{mol} / \mathrm{l}$ & $33(18.6 \%)$ & $44(24.9 \%)$ & $66(34.2 \%)$ & $144(26.3)$ & 0.003 \\
\hline Hypertension & $125(70.6 \%)$ & $116(65.5 \%)$ & $127(65.8 \%)$ & $370(67.6 \%)$ & 0.513 \\
\hline Diabetes mellitus & $48(27.1 \%)$ & $59(33.3 \%)$ & $52(26.9 \%)$ & $159(29.1 \%)$ & 0.315 \\
\hline Hypercholesterolemia & 67 (37.9\%) & $73(41.2 \%)$ & $82(42.5 \%)$ & $222(40.6 \%)$ & 0.648 \\
\hline Current smoker & $71(40.1 \%)$ & $60(33.9 \%)$ & $89(46.1 \%)$ & $220(40.2 \%)$ & 0.057 \\
\hline Stroke & $24(13.6 \%)$ & $13(7.3 \%)$ & $20(10.4 \%)$ & $57(10.4 \%)$ & 0.16 \\
\hline Chronic pulmonary disease & $17(9.6 \%)$ & $21(11.9 \%)$ & $24(12.4 \%)$ & $62(11.3 \%)$ & 0.667 \\
\hline Previous Ml & $9(5.1 \%)$ & $15(8.5 \%)$ & $8(4.1 \%)$ & $32(5.9 \%)$ & 0.181 \\
\hline Previous PCl & $6(3.4 \%)$ & $11(6.2 \%)$ & $3(2.6 \%)$ & $20(3.6 \%)$ & 0.182 \\
\hline SS & $4.81 \pm 2.21$ & $12.86 \pm 2.66$ & $26.07 \pm 6.83$ & $14.90 \pm 8.83$ & $<0.0001$ \\
\hline \multicolumn{6}{|l|}{ Indication for treatment } \\
\hline Stable angina & 60 (33.9\%) & $76(42.9 \%)$ & $69(35.8 \%)$ & $205(37.4 \%)$ & 0.177 \\
\hline Unstable angina & $53(29.9 \%)$ & $41(23.2 \%)$ & $57(29.5 \%)$ & $151(27.6 \%)$ & 0.174 \\
\hline ST-segment elevation MI & $27(15.3 \%)$ & $26(14.7 \%)$ & $34(17.6 \%)$ & $87(15.9 \%)$ & 0.714 \\
\hline Non-ST-segment elevation Ml & $15(8.5 \%)$ & $14(7.9 \%)$ & $7(3.6 \%)$ & $36(6.6 \%)$ & 0.118 \\
\hline Silent ischemia & $22(12.4 \%)$ & $19(10.7 \%)$ & $27(14.0 \%)$ & $27(12.4 \%)$ & 0.638 \\
\hline \multicolumn{6}{|l|}{ Medication at discharge } \\
\hline Aspirin & $144(81.4 \%)$ & $141(80.1 \%)$ & $172(89.1 \%)$ & $457(83.5 \%)$ & 0.038 \\
\hline Clopidogrel & $139(78.5 \%)$ & $149(84.2 \%)$ & 164 (85.0\%) & $452(82.6 \%)$ & 0.211 \\
\hline$\beta$-Blocker & 88 (49.7\%) & 93 (52.5\%) & $90(46.6 \%)$ & 90 (49.5\%) & 0.524 \\
\hline Statin & 139 (78.5\%) & $146(82.5 \%)$ & 165 (85.5\%) & $271(85.5 \%)$ & 0.215 \\
\hline ACEI/ARB & 82 (46.3\%) & 92 (52.0\%) & 82 (42.5\%) & $256(46.8 \%)$ & 0.186 \\
\hline
\end{tabular}

Value are $\mathrm{n}(\%)$, mean $\pm \mathrm{SD}$

MI myocardial infarction, $P C I$ percutaneous coronary intervention, SS SYNTAX score, SYNTAX Synergy Between Percutaneous Coronary Intervention with Taxus and Cardiac Surgery, $A C E I$ angiotensin converting enzyme inhibitors, $A R B$ angiotensin receptor blocker

revascularization (either PCI or CABG). The detailed definitions of each endpoints in current study were provided as below. All deaths were considered cardiogenic death unless a definite non-cardiogenic cause was recorded. Stroke was diagnosed by neurologists and was defined as a focal neurological deficit of vascular origin lasting for longer than $24 \mathrm{~h}$. MI was defined according to definitions from Academic Research Consortium as the presence of new $\mathrm{Q}$-waves of at least $0.4 \mathrm{~s}$ duration in $\geq 2$ contiguous leads and elevation of cardiac enzyme. In those patients without pathologic Q-waves, MI was defined as the elevation of the creatine kinase level to $>2 x$ of the upper limit of normal range, together with elevated level of creatine kinase MB or troponin I. Target-vessel revascularization or TLR was defined as an interventive procedure of either PCI or CABG for treatment of a stenosis within previous $\mathrm{PCI}$ treated vessel. Ischemia driven any repeat revascularization was defined by lumen stenosis $\geq 50 \%$ angiographically in the presence of ischemic symptoms, or stenosis $\geq 70 \%$ regardless of ischemic symptoms or signs. Stent thrombosis was defined as probable or definite, according to the recommendation of Academic Research Consortium.

\section{Statistical analysis}

Statistical analysis was performed using the Windows version of SPSS (ver. 19.0 SPSS, Inc, Chicago, IL, USA). All patients with calculated SS and CSS scores were included in the analysis. All continuous variables were in the form of mean and standard deviation (SD). All categorical variables were shown as counts and percentages. The Kolmogorov-Smirnov test was used for normality 

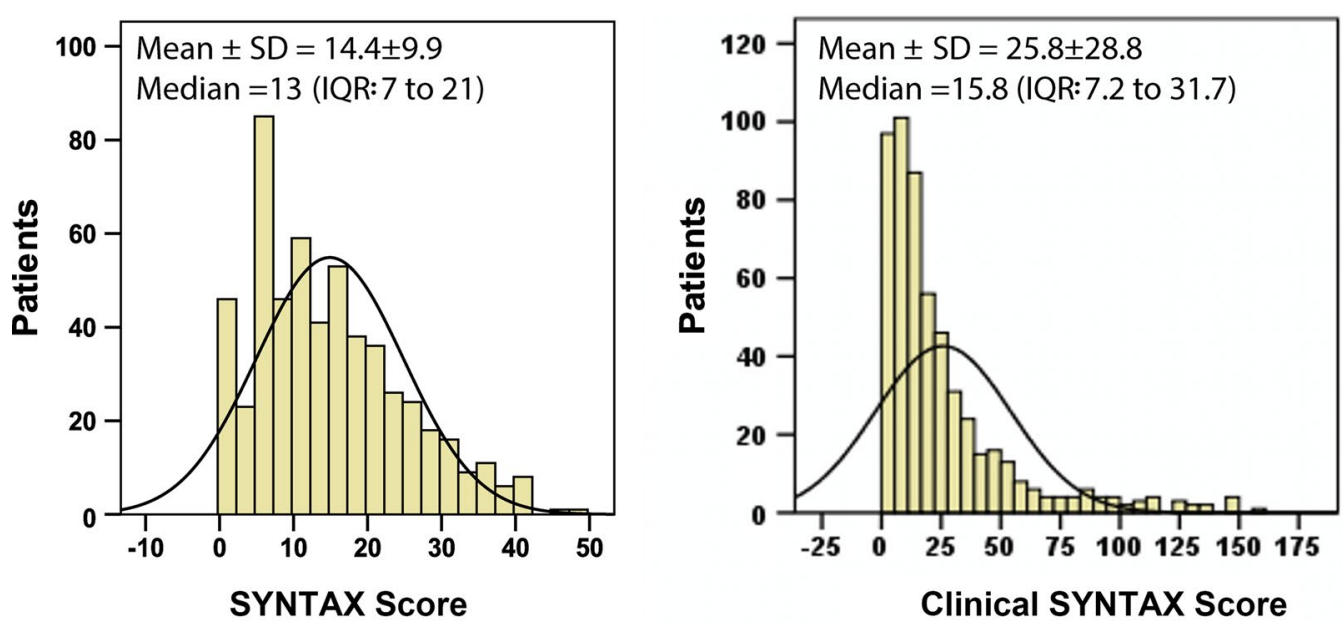

Fig. 1 Distribution of SS and CSS among the 547 patients enrolled in the study. Histograms of the SS (left side) and CSS (right side) with a superimposed normal curve. Both score distributions are skewed to right, and not normally distributed. Mean \pm SD values and median values plus inter-quartile range (IQR) are reported

assessment of the SS and CSS distribution. All variables were stratified according to SS/CSS tertiles. The correlation between SS and CSS was assessed by Spearman's test. Comparisons for continuous variables with a normal distribution were performed by one-way analysis of variance (ANOVA) and Chi-square test was used for all categorical variables. Time to event trends were demonstrated as Kaplan-Meier curve, and Log-rank test was used to assess the differences in survival among subgroups of patients.

The prognostic value of the SS and CSS was assessed by plotting the receiver-operator characteristic curves (ROCs), in which 0.50 indicates no discrimination and 1.0 indicates perfect discrimination. Areas-under-thecurves (AUCs) for SS and CSS were compared with the DeLong method using Windows version of MedCalc (ver. 11.6.0.0 MedCalc Software). Finally, to evaluate whether CSS is superior in the risk stratification comparing to SS, a net reclassification improvement analysis was performed.

To rule out potential confounders, univariable and multivariable Cox proportional hazard regression models was used to assess the relationship between SS/CSS and the incidence of primary endpoint. The variables were chosen according to their clinical significance. The following variables including sex, diabetes mellitus (DM), estimated glomerular filtration rate (eGFR), smoking, acute coronary syndrome (ACS), number of stents implanted, were tested on a per patient basis to determine suitability for inclusion in the multivariate model by univariate analysis.
All statistical tests were 2-tailed, and a $p$ value of less than 0.05 were considered as statistically significant.

\section{Results}

\section{Baseline clinical characteristics}

Baseline clinical and risk factors of the study population, stratified according to SS tertile were presented in Table 1.

The SS was available for 547 patients (1314 lesions in total, with an average of $2.4 \pm 1.4$ lesions for each patient) enrolled in current study. Overall, the SS ranged from 1 to 47.5 , with a mean of $14.90 \pm 8.83$ and a median of 13.00. The CSS ranged from 0.9 to 158.2 , with a mean of $25.80 \pm 15.23$ and a median of 15.80. Expectedly, there was a strong correlation between the two scores $(\mathrm{r}=0.713, p<0.001)$. The distributions of the two scores within the study population were shown in Fig. 1. Both scores were not normally distributed (KolmogorovSmirnov test both $p<0.001)$ but skewed to the right. In this analysis, patients were categorized according to tertile of the SS and CSS as follows: $\mathrm{SS}_{\mathrm{LOW}} \leq 8$ $(\mathrm{n}=177), 8<\mathrm{SS}_{\mathrm{MID}}<18(\mathrm{n}=177), 18 \leq \mathrm{SS}_{\mathrm{HIGH}}(\mathrm{n}=193)$; $\mathrm{CSS}_{\text {LOW }} \leq 10 \quad(\mathrm{n}=180), \quad 10<\mathrm{CSS}_{\text {MID }} \leq 25 \quad(\mathrm{n}=185)$, $25<\mathrm{CSS}_{\mathrm{HIGH}}(\mathrm{n}=182)$, respectively.

The mean age was $66.82 \pm 3.50$ with $68.2 \%$ male predominance. There were 159 (29.1\%) patients with diabetes mellitus, $68.3 \%$ patients with hypertension. Only 32 (5.9\%) patients had myocardial infarction history. Of all enrolled patients, almost one in two patients $(274 / 547$, $50.1 \%)$ presented with ACS, among which, 151 presenting unstable angina, 87 presenting ST-Elevation 
Table 2 Angiographic and procedural characteristics stratified according to SS tertile

\begin{tabular}{|c|c|c|c|c|c|}
\hline Variable & $\mathrm{SS}_{\text {low }} \leq 8(177)$ & $8<\mathrm{SS}_{\mathrm{mid}}<18(177)$ & $18 \leq \mathrm{SS}_{\text {high }}(193)$ & Total & $p$ value \\
\hline \multicolumn{6}{|l|}{ Diseased lesions } \\
\hline Number of disease lesions & $1.5 \pm 0.7$ & $2.1 \pm 1.0$ & $3.3 \pm 1.3$ & $2.3 \pm 1.6$ & $<0.001$ \\
\hline 1-Vessel disease & $131(74.0 \%)$ & $46(26.0 \%)$ & $5(2.6 \%)$ & $182(33.3 \%)$ & $<0.001$ \\
\hline 2-Vessel disease & $40(22.6 \%)$ & $86(48.6 \%)$ & $59(30.6 \%)$ & $185(33.8 \%)$ & $<0.001$ \\
\hline 3-Vessel disease & $6(3.4 \%)$ & 45 (25.4\%) & $129(66.8 \%)$ & $180(32.9 \%)$ & $<0.001$ \\
\hline \multicolumn{6}{|l|}{ Lesion location } \\
\hline Left main stem & $0(0.0 \%)$ & $3(1.7 \%)$ & $33(17.1 \%)$ & $36(6.6 \%)$ & $<0.001$ \\
\hline Left anterior artery & $95(53.7 \%)$ & $162(91.5 \%)$ & $185(95.9 \%)$ & $442(80.8 \%)$ & $<0.001$ \\
\hline Circumflex artery & $53(29.9 \%)$ & 81 (45.8\%) & $150(77.7 \%)$ & $284(51.9 \%)$ & $<0.001$ \\
\hline Right artery & 81 (45.8\%) & $107(60.5 \%)$ & $157(81.3 \%)$ & $345(63.1 \%)$ & $<0.001$ \\
\hline \multicolumn{6}{|l|}{ Lesion characteristics } \\
\hline Bifurcated lesion & $31(17.5 \%)$ & 99 (55.9\%) & $150(77.7 \%)$ & $280(51.2 \%)$ & $<0.001$ \\
\hline Trifurcated lesion & $0(0.0 \%)$ & $4(2.3 \%)$ & $17(8.8 \%)$ & $21(3.8 \%)$ & $<0.001$ \\
\hline Ostial lesion & $8(4.5 \%)$ & $6(3.4 \%)$ & $10(5.2 \%)$ & $24(4.4 \%)$ & 0.669 \\
\hline Lesion > 20 mm & $11(6.2 \%)$ & $48(27.1 \%)$ & $108(56.0 \%)$ & $167(30.5 \%)$ & $<0.0001$ \\
\hline Lesion with thrombus & $1(0.6 \%)$ & $1(0.6 \%)$ & $7(3.6 \%)$ & $9(1.6 \%)$ & $<0.0001$ \\
\hline Calcified lesion & $3(1.7 \%)$ & 19 (10.7\%) & $53(27.5 \%)$ & $75(13.7 \%)$ & $<0.0001$ \\
\hline Total occlusion & $1(0.6 \%)$ & $14(7.9 \%)$ & $64(33.2 \%)$ & $79(14.4 \%)$ & $<0.0001$ \\
\hline Chronic total occlusion & $0(0.0 \%)$ & $3(1.7 \%)$ & $34(17.6 \%)$ & $37(6.8 \%)$ & $<0.0001$ \\
\hline \multicolumn{6}{|l|}{ Treated coronary } \\
\hline 3-Vessel intervention & $1(0.6 \%)$ & $14(7.9 \%)$ & $39(20.2 \%)$ & $54(9.9 \%)$ & $<0.0001$ \\
\hline Left main stem & $0(0.0 \%)$ & $2(1.1 \%)$ & $0(0.0 \%)$ & $2(0.4 \%)$ & $<0.0001$ \\
\hline Left anterior descending & $84(47.5 \%)$ & $125(70.6 \%)$ & $91(47.2 \%)$ & $300(54.8 \%)$ & $<0.0001$ \\
\hline Circumflex & $41(23.2 \%)$ & $34(19.2 \%)$ & $43(22.3 \%)$ & $118(21.6 \%)$ & 0.636 \\
\hline Right & $68(38.4 \%)$ & $70(39.5 \%)$ & $84(43.5 \%)$ & $222(40.6 \%)$ & 0.573 \\
\hline \multicolumn{6}{|l|}{ Procedural characteristics } \\
\hline Number of implanted stents & $1.6 \pm 0.9$ & $2.1 \pm 1.0$ & $3.0 \pm 1.3$ & $2.2 \pm 1.5$ & $<0.0001$ \\
\hline Total stent length/patient (mm) & $29.3 \pm 16.8$ & $41.1 \pm 28.0$ & $64.3 \pm 30.7$ & $66.3 \pm 32.5$ & $<0.0001$ \\
\hline Maximal pressure of stent deployment & $13.8 \pm 2.6$ & $13.0 \pm 2.8$ & $14.8 \pm 2.7$ & $13.8 \pm 1.7$ & $<0.0001$ \\
\hline Patients with complete revascularization & $147(83.1 \%)$ & $91(51.4 \%)$ & $25(13 \%)$ & $263(48.1 \%)$ & $<0.0001$ \\
\hline Use of glycoprotein IIb/IIla inhibitors & $0(0.0 \%)$ & $5(2.8 \%)$ & $16(8.3 \%)$ & $21(4.8 \%)$ & $<0.0001$ \\
\hline Post-procedural hospital stay, days & $10.0 \pm 5.9$ & $9.6 \pm 5.0$ & $12.4 \pm 9.6$ & $10.6 \pm 4.6$ & 0.001 \\
\hline Intravascular imaging & $0(0.0 \%)$ & $1(0.2 \%)$ & $7(1.3 \%)$ & $8(1.5 \%)$ & $<0.0001$ \\
\hline
\end{tabular}

Value are $n(\%)$, mean $\pm S D$

SS SYNTAX score

Myocardial Infarction (STEMI), 36 presenting Non-STelevation myocardial infarction (NSTEMI).

The percentage of patients with 1-vessel, 2-vessel and 3-vessel lesion was 33.3\%, 33.8\% and 32.9\%, respectively (Table 2). Complete revascularization was achieved in $265(48.1 \%)$ patients, the percentage of patients underwent complete revascularization was $83.1 \%$ (147), $51.4 \%$ (91), $13.0 \%(25)$ in $\mathrm{SS}_{\mathrm{LOW}}$, in $\mathrm{SS}_{\mathrm{MED}}$ and in $\mathrm{SS}_{\mathrm{HIGH}}$ tertile, respectively (Table 2).

Only $36(6.6 \%)$ patients had lesions involving the left main stem. $345(63.1 \%)$ patients had right coronary artery DS $>50 \% .441$ (80.8\%) patients had lesions located within the left anterior descending artery.
Angiographic and procedural characteristics

Baseline lesion and procedural characteristics were shown in Table 2. Markers which increase lesion complexity, such as the presence of bifurcation lesions, long lesions, calcification, and total occlusions were all significantly higher in the $\mathrm{SS}_{\mathrm{HIGH}}$ tertile.

In $\mathrm{SS}_{\mathrm{HIGH}}$ tertile, the mean number of significant lesions for each patient was 3.3, received 3.0 stents with an average total stented length of $64.3 \mathrm{~mm}$ with the mean maximal air pressure 14.8 for stent deployment; all of which were significantly higher. Moreover, post-procedure in hospital stay was also significantly longer in the $\mathrm{SS}_{\mathrm{HIGH}}$ tertile. 
Table 3 Clinical outcomes 2 years since date of procedural according to SS

\begin{tabular}{lcccc}
\hline Variable & SSlow $\leq \mathbf{8}(\mathbf{1 7 7})$ & $\mathbf{8}<$ SSmid < 18 (177) & $\mathbf{1 8} \leq$ SShigh (193) & $\boldsymbol{p}$ value \\
\hline MACCE** & $0(0 \%)$ & $12(6.8 \%)$ & $26(13.5 \%)$ & $8(4.1 \%)$ \\
All-cause death & $3(1.7 \%)$ & $6(3.4 \%)$ & $11(5.7 \%)$ & 0.0001 \\
Target vessel failure & $0(0 \%)$ & $4(2.3 \%)$ & $14(7.3 \%)$ & 0.385 \\
Any repeat revascularization & $0(0 \%)$ & $7(4.0 \%)$ & $0(0 \%)$ & 0.003 \\
Stroke & $0(0 \%)$ & $3(1.7 \%)$ & $4(2.1 \%)$ & 0.045 \\
ARC stent thrombosis* & $0(0 \%)$ & $1(0.6 \%)$ & $30(15.6 \%)$ & 0.094 \\
Hospitalization due to angina pectoris & $17(9.6 \%)$ & $3(1.7 \%)$ & $8(4.2 \%)$ & 0.113 \\
Cardiac death & $0(0 \%)$ & 0.016 \\
\hline
\end{tabular}

Values are $\mathrm{n}(\%)$, mean $\pm \mathrm{SD}$

ACS acute coronary syndrome

*Defined according to the Academic Research Consortium (ARC)

\# Target lesion failure: cardiac death, target-vessel driven myocardium infraction, ischemia-driven target lesion revascularization (TLR)

**MACCE: cardiac death, any $\mathrm{MI}$, any repeat revascularization and stroke

Table 4 Clinical outcomes 2 years since date of procedural according to CSS

\begin{tabular}{|c|c|c|c|c|}
\hline Variable & $\operatorname{CSS}_{\text {Low }}(180)$ & $\mathrm{CSS}_{\mathrm{MID}}(185)$ & $\mathrm{CSS}_{\mathrm{HIGH}}(182)$ & $p$ value \\
\hline MACCE** & $3(1.7 \%)$ & $7(3.8 \%)$ & $28(15.4 \%)$ & $<0.0001$ \\
\hline All-cause death & $1(0.6 \%)$ & $4(2.2 \%)$ & $12(6.6 \%)$ & 0.003 \\
\hline Target vessel failure ${ }^{\#}$ & $0(0 \%)$ & $4(2.2 \%)$ & $11(6.0 \%)$ & 0.002 \\
\hline Any repeat revascularization & $3(1.7 \%)$ & $4(2.2 \%)$ & $14(7.7 \%)$ & 0.004 \\
\hline Stroke & $0(0 \%)$ & $1(0.5 \%)$ & $2(1.1 \%)$ & 0.367 \\
\hline ARC stent thrombosis* & $0(0 \%)$ & $4(2.2 \%)$ & $1(0.5 \%)$ & 0.078 \\
\hline Hospitalization due to angina pectoris & $19(10.6 \%)$ & $25(13.8 \%)$ & $64(11.7 \%)$ & 0.563 \\
\hline Cardiac death & $0(0 \%)$ & $1(0.5 \%)$ & $10(5.5 \%)$ & $<0.0001$ \\
\hline
\end{tabular}

Values are $\mathrm{n}(\%)$, mean $\pm \mathrm{SD}$

* Defined according to the Academic Research Consortium (ARC)

\# Target lesion failure: cardiac death, target-vessel driven myocardium infraction, ischemia-driven target lesion revascularization (TLR)

${ }^{*}$ MACCE: cardiac death, any $\mathrm{MI}$ any repeat revascularization and stroke

\section{SYNTAX score versus clinical SYNTAX score}

Clinical outcomes across SS tertiles were shown in Table 3, the rate of MACCE, Target lesion failure (TLF, including cardiac death, target-vessel driven myocardial infarction, ischemia-driven target lesion revascularization), cardiac death, MI and any repeat revascularization were significant higher in the $\mathrm{SS}_{\mathrm{HIGH}}$ tertile. During the follow-up period, 17 patients died. The rates of all-cause death in three group were $1.7 \%$ in $\mathrm{SS}_{\mathrm{LOW}}$ tertile, $3.4 \%$ in $\mathrm{SS}_{\mathrm{MED}}$ tertile and $4.1 \%$ in $\mathrm{SS}_{\mathrm{HIGH}}$ tertile. Three patients died of definite non-cardiogenic cause (one died of traffic accident, one died of pulmonary carcinoma and another died of cerebral hemorrhage) were categorized into $\mathrm{SS}_{\text {LOW }}$ tertile.

Clinical outcomes stratified CSS tertile were shown in Table 4. Comparing with those stratified by SS, CSS yielded similar results when comparing between the high and low risk group. However, in contrast to the SS analysis, there was significant difference in event rates for all-cause death between high and low CSS tertile.

\section{Kaplan-Meier analysis}

As shown in Fig. 2A, the MACCE-free survival was significantly lower in $\mathrm{SS}_{\mathrm{HIGH}}$ compared with $\mathrm{SS}_{\mathrm{LOW}}(86.5 \%$ vs. $100 \%, p<0.0001$ ), such trend was also observed for survival rates of endpoints TLF ( $94.3 \%$ vs. $100 \%, p=0.03$ ) and cardiac death/MI ( $94.3 \%$ vs. $100 \%, p=0.02)$. However, no trends were observed among the free survival rate of all-cause death $(98.3 \%$ in the low, $96.6 \%$ in the median, $95.9 \%$ in the high, $p=0.377$ ).

Clinical outcomes across by CSS tertile were shown in Fig. 2B. Survival curve of all-cause death was significantly higher in $\mathrm{CSS}_{\mathrm{HIGH}}$ compare with $\mathrm{CSS}_{\mathrm{LOW}}$ (Fig. 2B). The survival rate of MACCE, TLF and cardiac death/MI were also significantly higher in $\mathrm{CSS}_{\mathrm{HIGH}}$ compared with $\mathrm{CSS}_{\text {LOW }}$ tertile, similar to results from SS tertile. 

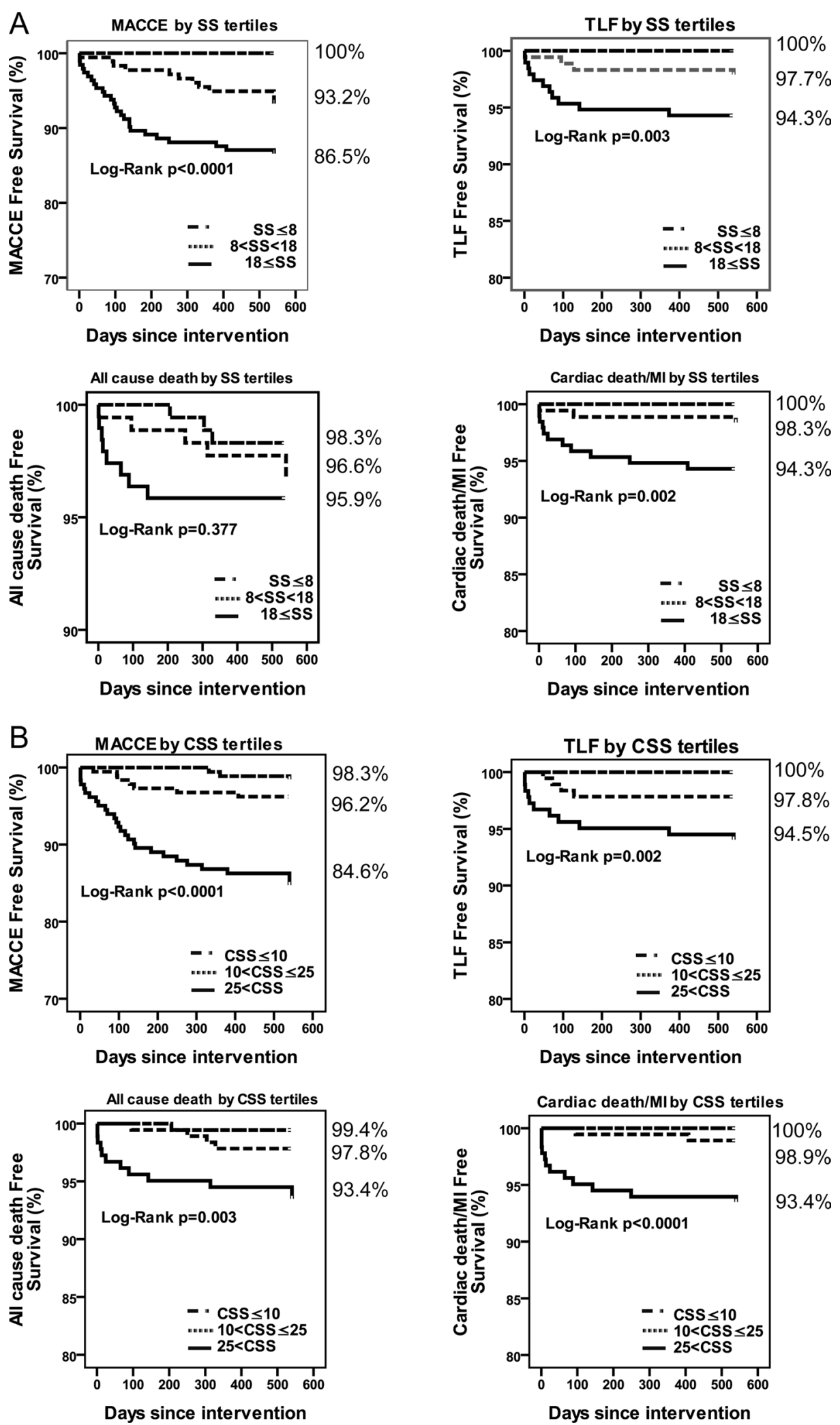

Fig. 2 Clinical outcomes at 2-year follow up stratified by SS (A) and CSS (B) tertile. Kaplan-Meier curves are presented for major adverse cardiac and cerebral events, target lesion failure, all-cause death and cardiac death/myocardial infarction 

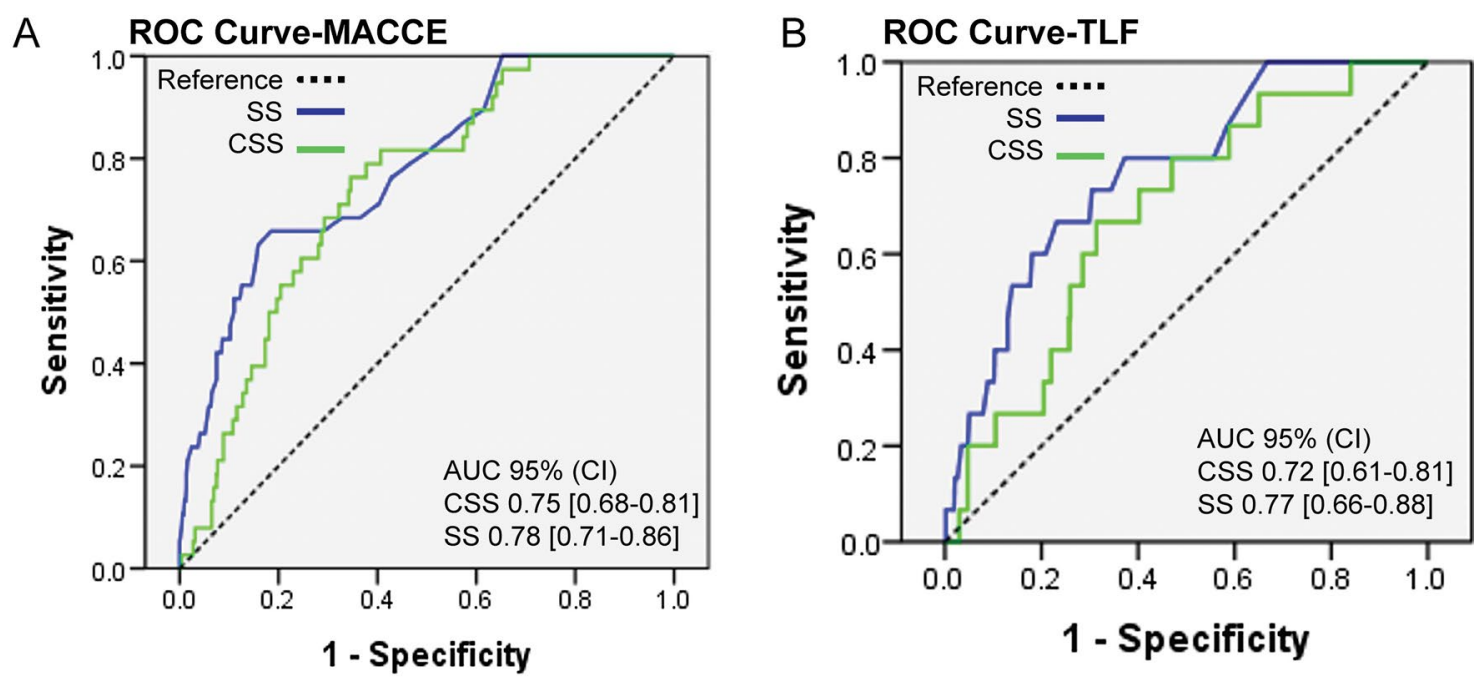

ROC Curve-All cause death
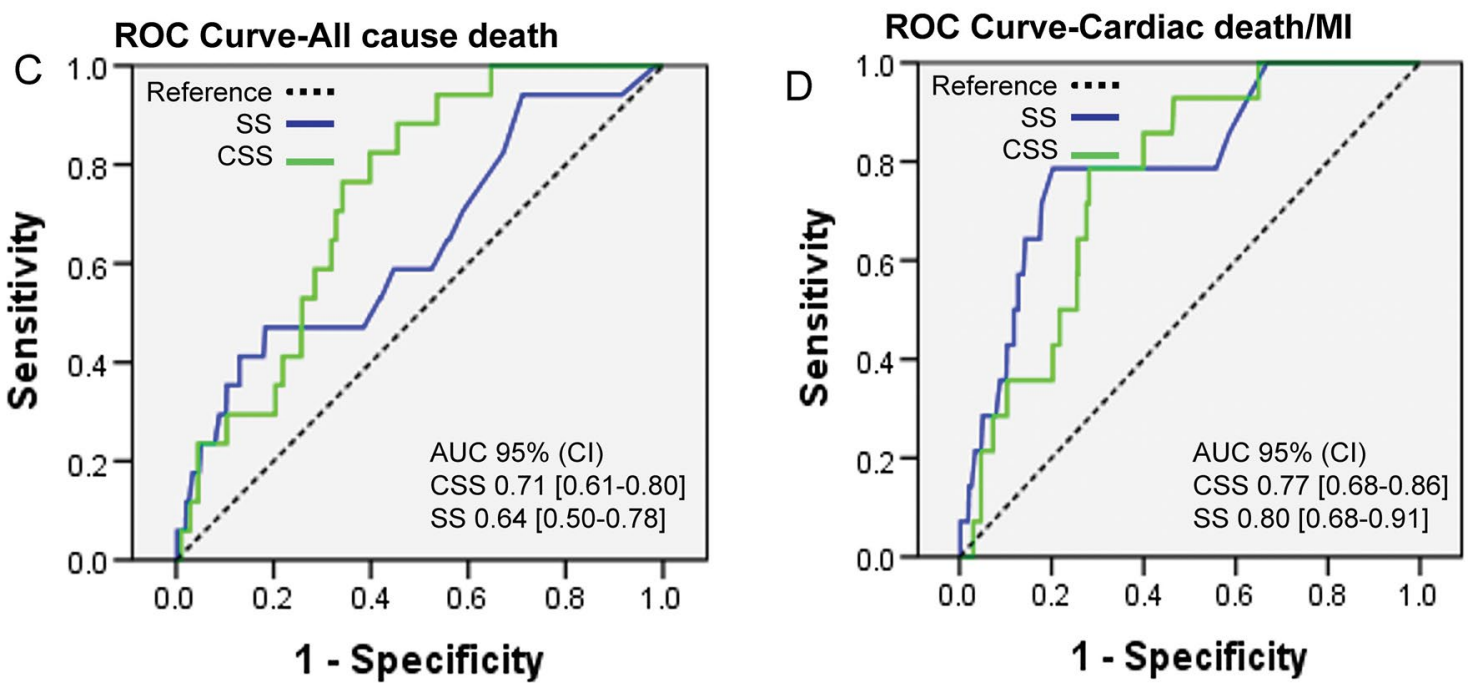

Fig. 3 Receiver operating characteristic (ROC) curves for SS and CSS. (A) major adverse cardiac and cerebral events (B) target lesion failure (C) all-cause death (D) cardiac death/myocardium infarction. AUC area-under-the-curve, Cl confidence interval, SS SYNTAX score, CSS clinical SYNTAX score

Table 5 COX multivariable analysis

\begin{tabular}{llccc}
\hline Clinical outcome & Hazard ratio for CSS $\mathbf{9 5 \%}$ Cl) & $\boldsymbol{p}$ value & Hazard ratio for SS $(\mathbf{9 5 \%}$ Cl)* & $\boldsymbol{p}$ value \\
\hline All-cause death & $1.012(1.000-1.024)$ & 0.049 & $1.049(1.005-1.095)$ & 0.027 \\
Target lesion failure & $1.014(1.001-1.028)$ & 0.034 & $1.090(1.042-1.140)$ & $<0.0001$ \\
Cardiac death/MI & $1.018(1.004-1.030)$ & 0.006 & $1.100(1.049-1.153)$ & $<0.0001$ \\
MACCE & $1.017(1.009-1.022)$ & $<0.0001$ & $1.101(1.070-1.134)$ & $<0.0001$ \\
Any Ml & $1.024(1.002-1.047)$ & 0.034 & $1.105(1.010-1.209)$ & 0.03 \\
Any repeat revascularization & $1.018(1.008-1.029)$ & $<0.0001$ & $1.107(1.064-1.152)$ & $<0.0001$
\end{tabular}

Cl confidence interval, HR hazard ratio, ACS acute coronary syndrome, MACCE major adverse cardiac and cerebral events, SS SYNTAX score, CSS clinical SYNTAX score 
Table 6 MACCE reclassification into CSS tertile

\begin{tabular}{lcccc}
\hline & CSS $_{\text {Low }}$ & CSS $_{\text {MID }}$ & CSS $_{\text {HIGH }}$ & Total \\
\hline Patients with & MACCE events & & & \\
SS $_{\text {Low }}$ & 0 & 0 & 0 & 0 \\
SS $_{\text {MID }}$ & 2 & 0 & 4 & 6 \\
SS $_{\text {HIGH }}$ & 0 & 4 & 0 & 4 \\
Total & 2 & 4 & 4 & 10 \\
Patients without MACCE events & & & \\
SS & 149 & 25 & 3 & 178 \\
SS $_{\text {MID }}$ & 29 & 92 & 49 & 160 \\
SS $_{\text {HIGH }}$ & 0 & 63 & 126 & 189 \\
Total & 178 & 181 & 178 & 537 \\
\hline
\end{tabular}

\section{The ROC curve analysis}

The receiver operating characteristic (ROC) curves for MACCE, TLF, all-cause death and cardiac death/ MI during 2-year follow-up were shown in Fig. 3A-D. In this analysis, the areas under the curves (AUC) of both scores were significantly (both $p<0.001$ ) higher than the area of diagnostic indifference. However, we found the AUC is not larger for CSS MACCE (AUC SS, 0.78; AUC CSS, 0.75), TLF (AUC SS, 0.77; AUC CSS, 0.72 ) and cardiac death/MI (AUC SS, 0.80; AUC CSS, 0.70 ). The AUC for all-cause death by CSS was slightly larger comparing to SS but not significant (AUC SS, 0.64; AUC CSS, 0.71; $p=0.23$ ) (Fig. 3C). The optimal cut-points were selected using the common method of Youden index method. Optimal cut-points were calculated as 21.00 for SS and 45.35 for CSS. We calculated the Youden index, positive and negative prediction values. Youden index is 0.38 and 0.46 for SS and CSS, respectively. Positive/negative prediction value is $20.62 \% / 96.00 \%$ for SS and $23.47 \% / 96.65 \%$ for CSS.
These results suggested comparable prediction ability comparing SS and CSS in our study population.

\section{Cox multivariable analysis}

The results of COX multivariable analysis were shown in Table 5. After adjust confounding factors including age, sex, DM, presentation with ACS, number stent implanted, the SS remained as an independent predictor for MACCE [1.101 (1.070-1.134), $p<0.0001]$. The CSS remained as an independent predictor for all-cause death at 2-year follow up [1.012 (1.000-1.024), $p<0.05]$.

\section{Reclassifying from SS into CSS tertile}

When reclassifying patients with MACCE from SS tertiles into CSS tertiles, 4/10 (40.0\%) patients with events were moved to higher risk categories (upward) and $6 / 10(60.0 \%)$ to lower risk categories (downward) with a net difference of $20.0 \%$. In patients without MACCE, 92/537 (17.1\%) were moved downward and 77/537 (14.3\%) upward, with a net difference of $2.8 \%$, as shown in Table 6 and Fig. 4.

\section{Discussion}

The prognostic value of the SS have been well proved both in large-scale registry or a randomized controlled trial [6]. The main findings of this study indicated that both SS and CSS are valuable in the risk stratification of long-term clinical outcomes in an all-comers Chinese population receiving drug-eluting stents. Both scores were identified as independent predictors for MACCE but the CSS was also an independent predictor for all cause death. Although the SS was an angiographic scoring system that was developed in an attempt to risk stratification of patients undergoing

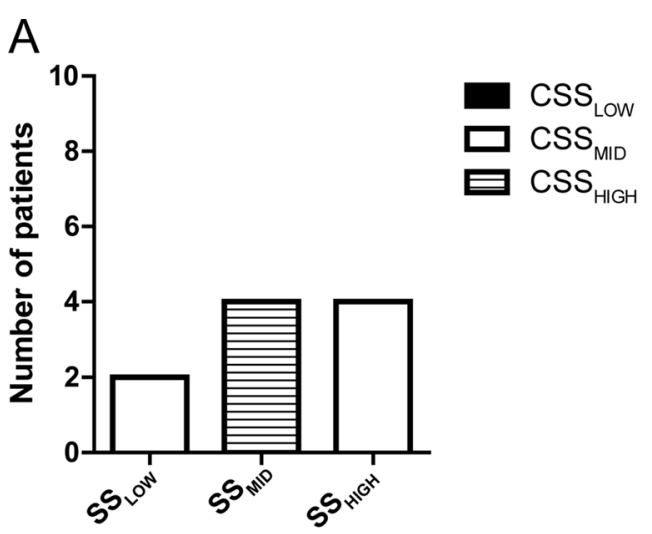

Patients with MACCE events

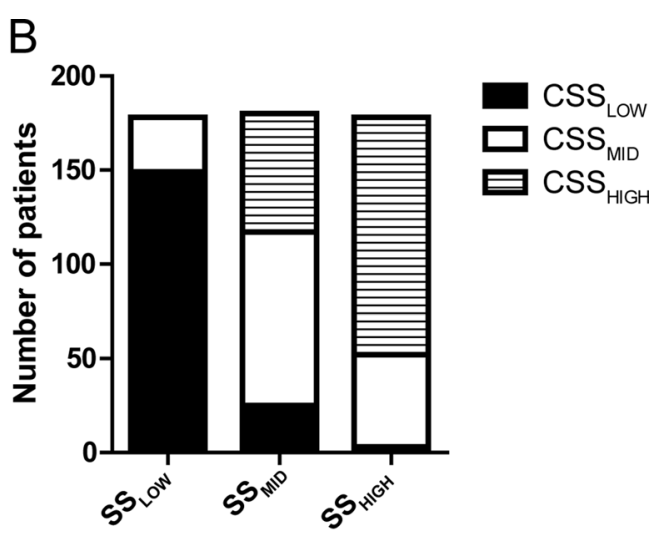

Patients without MACCE events

Fig. 4 Reclassification of patients from SS tertiles to CSS tertiles 
revascularization of the left main coronary artery and/or the 3 main coronary arteries [17]. However, we found that other than patients involved LM undergoing PCI, the SS still remained as an independent predictor for MACCE in low and moderate risk patients. Therefore, the SS also has the ability to predict the clinical outcomes in low and median risk patients with PCI.

Consistent with previous results, this study also showed that the SS have the ability to stratify patients into different risk categories of adverse events after PCI [15]. However, we showed that the event rate of MACCE was the highest in $\mathrm{SS}_{\mathrm{HIGH}}$ tertile, but the event rate of allcause death was not statistically different. In addition, some studies argue that the SS only plays a partial role in predicting long-term adverse events after PCI and calls for incorporation of traditional well-recognized clinical risk factors in risk evaluation [6]. To address this question, several scoring systems have been developed for patients underwent PCI, however, few are being used by physicians in clinical practice. These scoring systems include the AHA/ACC score (American College of Cardiology/American Heart Association) [18], EuroSCORE (European System for Cardiac Operative Risk Evaluation) [19], global risk classification [20] and Parsonnet score [21], et al. These risk models used a selection of clinical variables that had been identified as predictors of adverse outcome in patients with PCI.

Recently, Garg et al. combined the SS with modified ACEF score (incorporating age, left ventricular ejection fraction, and creatinine clearance) to produce CSS. They found that, the AUC for CSS was significantly larger compared to that of SS regarding all-cause death (0.66 vs. $0.58, p<0.001)$ [22] suggesting better accuracy. After the study of Garg et al., there have been studies comparing the prognostic value of the SS and CSS on the outcomes of ACS patients undergoing PCI $[15,23]$. In the study of He et al., CSS demonstrated significantly improved capability in predicting 2-year cardiac death as analyzed by receiver-operating characteristic curve, but not for prediction of MACE [23]. Girasis et al. reported AUC of CSS was significantly larger compared to that of SS regarding cardiac death and all-cause mortality, but not significant for MACE [15]. In our study, SS showed a tendency of larger AUC for CSS in terms of all cause death, but not for MACCE, TLF and cardiac death/MI. This is mostly likely because, in this study, only a small percentile of patients had lesions involving the left main (LM) stem, but more than half of patients had 1-vessel or 2-vessel disease, and a majority of the enrolled population are at low or moderate risk comparing to other studies whether most patients are at higher risk.

\section{Study limitations}

The study has the following limitations. First, this study was single center design, intra- and inter-observer variability, which was inherent to coronary angiography cannot be ruled out. Secondly, the enrollment number was not big enough. Thirdly, the functional information of coronary circulation [24], like the fractional flow reserve (FFR) which was known to impact the clinical outcome, is lacking [25]. Finally, the retrospective design of the study, where patients have been categorized to be more clinically suitable for PCI instead of CABG may also pose an important bias.

\section{Conclusion}

Both SS and CSS containing clinical information were able to stratify risk of clinical outcomes in all-comers Chinese population treated with PCI using drug-eluting stents. In this study of Chinese patients underwent PCI, CSS performed comparable ability in predicting outcomes comparing with the SS.

\section{Acknowledgements \\ Not applicable.}

\section{Authors' contributions}

$X Q L$ and $C Y$ conceived the study and drafted the manuscript; $K C$ supervised the study; XQL and CY were responsible for data collection. XLL and WLW were responsible for analysis of data. All authors read and approved the final manuscript.

\section{Funding}

This study was supported by Science and Technology Planning Project of Yuzhong District of Chongqing (No. 20180124), Medical Science and Technology Innovation Project of Chongqing General Hospital (No. Y2016MSXM40 and Y2019ZDXM04), Medical Science and Technology Innovation Fund of Chongqing General Hospital (No. 2019ZDXM06).

Availability of data and materials

All original data used to support the findings of this study are available from the corresponding author upon reasonable request.

\section{Declarations}

\section{Ethics approval and consent to participate}

The study was in compliance with the Declaration of Helsinki and the study protocol was approved by the Institutional Review Board of Chongqing Medical University. Written informed consent was obtained from each participating patient at the time of enrollment.

\section{Consent for publication}

Not applicable.

\section{Competing interests}

The authors have no conflict of interest to disclose.

Received: 27 February 2021 Accepted: 26 June 2021

Published online: 07 July 2021 


\section{References}

1. Serruys PW, Onuma Y, Garg S, Sarno G, van den Brand M, Kappetein AP, Van Dyck N, Mack M, Holmes D, Feldman T. Assessment of the SYNTAX score in the Syntax study. Eurolntervention. 2009;5(1):50-6.

2. Sianos G, Morel MA, Kappetein AP, Morice MC, Colombo A, Dawkins K, van den Brand M, Van Dyck N, Russell ME, Mohr FW. The SYNTAX score: an angiographic tool grading the complexity of coronary artery disease. Eurolntervention. 2005;1(2):219-27.

3. Serruys PW, Morice MC, Kappetein AP, Colombo A, Holmes DR, Mack MJ, Ståhle E, Feldman TE, Van Den Brand M, Bass EJ. Percutaneous coronary intervention versus coronary-artery bypass grafting for severe coronary artery disease. N Engl J Med. 2009;360(10):961-72.

4. Capodanno D, Capranzano P, Di Salvo ME, Caggegi A, Tomasello D, Cincotta G, Miano M, Patané M, Tamburino C, Tolaro S. Usefulness of SYNTAX score to select patients with left main coronary artery disease to be treated with coronary artery bypass graft. JACC Cardiovasc Interv. 2009;2(8):731-8.

5. Ong AT, Serruys PW, Mohr FW, Morice M-C, Kappetein AP, Holmes DR Jr, Mack MJ, van den Brand M, Morel M-A, van Es G-A. The SYNergy between percutaneous coronary intervention with TAXus and cardiac surgery (SYNTAX) study: design, rationale, and run-in phase. Am Heart J. 2006;151(6):1194-204.

6. Kim YH, Park DW, Kim WJ, Lee JY, Yun SC, Kang SJ, Lee SW, Lee CW, Park SW, Park SJ. Validation of SYNTAX (Synergy between PCI with Taxus and Cardiac Surgery) score for prediction of outcomes after unprotected left main coronary revascularization. JACC Interv. 2010;3(6):612.

7. Valgimigli M, Serruys PW, Tsuchida K, Vaina S, Morel M-A, van den Brand MJ, Colombo A, Morice MC, Dawkins K, de Bruyne B. Cyphering the complexity of coronary artery disease using the syntax score to predict clinical outcome in patients with three-vessel lumen obstruction undergoing percutaneous coronary intervention. Am J Cardiol. 2007:99(8):1072-81.

8. Morice M-C, Serruys PW, Kappetein AP, Feldman TE, Ståhle E, Colombo A, Mack MJ, Holmes DR, Choi JW, Ruzyllo W. Five-year outcomes in patients with left main disease treated with either percutaneous coronary intervention or coronary artery bypass grafting in the synergy between percutaneous coronary intervention with taxus and cardiac surgery trial. Circulation. 2014;129(23):2388-94.

9. Feldman DN, Gade CL, Slotwiner AJ, Parikh M, Bergman G, Wong SC, Minutello RM. Comparison of outcomes of percutaneous coronary interventions in patients of three age groups $(<60,60$ to 80 , and $>80$ years) (from the New York State Angioplasty Registry+). Am J Cardiol. 2006:98(10):1334-9.

10. Shaw JA, Andrianopoulos N, Duffy S, Walton AS, Clark D, Lew R, Sebastian M, New G, Brennan A, Reid C. Renal impairment is an independent predictor of adverse events post coronary intervention in patients with and without drug-eluting stents. Cardiovasc Revasc Med. 2008;9(4):218-23.

11. Keelan PC, Johnston JM, Koru-Sengul T, Detre KM, Williams DO, Slater J, Block PC, Holmes DR. Comparison of in-hospital and 1-year outcomes in patients with left ventricular ejection fractions $\leq 40 \%, 41 \%$ to $49 \%$, and $\geq 50 \%$ having percutaneous coronary revascularization. Am J Cardiol. 2003;91(10):1168-72.

12. Ix JH, Mercado N, Shlipak MG, Lemos PA, Boersma E, Lindeboom W, O'Neill WW, Wijns W, Serruys PW. Association of chronic kidney disease with clinical outcomes after coronary revascularization: the Arterial Revascularization Therapies Study (ARTS). Am Heart J. 2005;149(3):512-9.

13. Wykrzykowska JJ, Garg S, Onuma Y, De Vries T, Goedhart D, Morel MA, Van Es GA, Buszman P, Linke A, Ischinger T. Value of age, creatinine, and ejection fraction (ACEF score) in assessing risk in patients undergoing percutaneous coronary interventions in the 'All-Comers" LEADERS TrialClinical Perspective.' Circ Cardiovasc Interv. 2011:4(1):47-56.

14. Ranucci M, Castelvecchio S, Menicanti L, Frigiola A, Pelissero G. Risk of assessing mortality risk in elective cardiac operations: age, creatinine, ejection fraction, and the law of parsimony. Circulation. 2009;119(24):3053-61.

15. Girasis C, Garg S, Räber L, Sarno G, Morel MA, Garcia-Garcia HM, Lüscher TF, Serruys PW, Windecker S. SYNTAX score and clinical SYNTAX score as predictors of very long-term clinical outcomes in patients undergoing percutaneous coronary interventions: a substudy of SIRolimus-eluting stent compared with pacliTAXel-eluting stent for coronary revascularization (SIRTAX) trial. Eur Heart J. 2011:32(24):3115-27.

16. Garg S, Sarno G, Garcia-Garcia HM, Girasis C, Wykrzykowska J, Dawkins $K D$, Serruys PW, Investigators A-I. A new tool for the risk stratification of patients with complex coronary artery disease: the clinical SYNTAX score. Circ Cardiovasc Interv. 2010;3(4):317-26.

17. Kappetein AP, Feldman TE, Mack MJ, Morice MC, Holmes DR, Ståhle E, Dawkins KD, Mohr FW, Serruys PW, Colombo A. Comparison of coronary bypass surgery with drug-eluting stenting for the treatment of left main and/or three-vessel disease: 3-year follow-up of the SYNTAX trial. Eur Heart J. 2011;32(17):2125-34.

18. Smith SC Jr, Feldman TE, Hirshfeld JW Jr, Jacobs AK, Kern MJ, King SB III, Morrison DA, O'Neill WW, Schaff HV, Whitlow PL. ACC/AHA/SCAI 2005 guideline update for percutaneous coronary intervention: a report of the American College of Cardiology/American Heart Association Task Force on Practice Guidelines (ACC/AHA/SCAI writing committee to update the 2001 guidelines for percutaneous coronary intervention). J Am Coll Cardiol. 2006;47(1):e1

19. Capodanno D, Miano M, Cincotta G, Caggegi A, Ruperto C, Bucalo R, Sanfilippo A, Capranzano P, Tamburino C. EuroSCORE refines the predictive ability of SYNTAX score in patients undergoing left main percutaneous coronary intervention. Am Heart J. 2010;159(1):103-9.

20. Capodanno D, Caggegi A, Miano M, Cincotta G, Dipasqua F, Giacchi G, Capranzano P, Ussia G, Di Salvo ME, La Manna A, et al. Global risk classification and clinical SYNTAX (synergy between percutaneous coronary intervention with TAXUS and cardiac surgery) score in patients undergoing percutaneous or surgical left main revascularization. JACC CardiovasC Interv. 2011;4(3):287-97.

21. Lawrence D, Valencia O, Smith E, Murday A, Treasure T. Parsonnet score is a good predictor of the duration of intensive care unit stay following cardiac surgery. Heart. 2000;83(4):429-32.

22. Garg S, Girasis C, Sarno G, Goedhart D, Morel MA, Garcia-Garcia HM, Bressers M, Es GA, Serruys PW. The SYNTAX score revisited: a reassessment of the SYNTAX score reproducibility. Catheter Cardiovasc Interv. 2010;75(6):946-52.

23. He C, Song $Y$, Wang $C S$, Yao $Y$, Tang XF, Zhao XY, Gao RL, Yang YJ, Xu $B$, Yuan JQ. Prognostic value of the clinical SYNTAX score on 2-year outcomes in patients with acute coronary syndrome who underwent percutaneous coronary intervention. Am J Cardiol. 2017;119(10):1493-9.

24. Nam CW, Mangiacapra F, Entjes R, Chung IS, Sels JW, Tonino PAL, De Bruyne B, Pijls NHJ, Fearon WF. Functional SYNTAX score for risk assessment in multivessel coronary artery disease. J Am Coll Cardiol. 2011;58(12):1211-8

25. Tonino PAL, De Bruyne B, Pijls NHJ, Siebert U, Ikeno F, vant Veer M, Klauss $\checkmark$, Manoharan G, Engstrøm T. Oldroyd KG. Fractional flow reserve versus angiography for guiding percutaneous coronary intervention. N Engl J Med. 2009;360(3):213-24

\section{Publisher's Note}

Springer Nature remains neutral with regard to jurisdictional claims in published maps and institutional affiliations.

Ready to submit your research? Choose BMC and benefit from:

- fast, convenient online submission

- thorough peer review by experienced researchers in your field

- rapid publication on acceptance

- support for research data, including large and complex data types

- gold Open Access which fosters wider collaboration and increased citations

- maximum visibility for your research: over 100M website views per year

At $\mathrm{BMC}$, research is always in progress.

Learn more biomedcentral.com/submissions 